\title{
El product placement en el videoclip: análisis de contenido del emplazamiento de marca en los vídeos musicales preferidos por los usuarios de YouTube
}

\section{Product Placement on Music Video: content analysis of brand placement in the YouTube users' favourite music videos}

\author{
José Patricio Pérez Rufí. Universidad de Málaga \\ José Luis Navarrete Cardero. Universidad de Sevilla \\ Francisco Javier Gómez Pérez. Universidad de Granada
}

Recibido: 29-III-2013 - Aceptado: 24-II-2014

Resumen:

Esta investigación estudia el emplazamiento de productos en el videoclip musical con mayor número de reproducciones en YouTube en el plazo de un mes. Entendemos el product placement como una técnica que mezcla diversas estrategias de comunicación publicitaria a partir de su presencia en el discurso audiovisual. Nuestro objetivo principal es conocer de qué forma se utiliza esta técnica de comunicación comercial en el formato del vídeo musical. Intentamos igualmente determinar su idoneidad para la transmisión de un mensaje comercial. Para lograr estos objetivos, realizamos un análisis de contenido de los 50 vídeos musicales con mayor número de reproducciones en YouTube durante el mes de enero de 2013. Aplicamos una metodología cuantitativa y cualitativa basada en la propuesta de Méndiz que enumera y valora la presencia de marcas. El análisis concluye que se trata de una estrategia comercial extraordinariamente frecuente, aunque no todos los vídeos resultan apropiados para ello. De igual forma, determinadas marcas y productos encuentran en el videoclip una vía idónea para introducir sus novedades en el mercado. La proximidad con el lenguaje del anuncio de televisión perjudica la credibilidad del discurso.

Palabras clave:

Emplazamiento de productos; videoclip; YouTube; publicidad; industrias culturales.

Abstract:

This paper studies the product placement in the YouTube most viewed music videos in a month. Product placement is a technique that mixes different commercial communication strategies when used in an audio-visual vehicle. The main goal of this research is to know the way in which is used this commercial communication technique in the music video. We try to establish the suitability of the musical audio-visual production to communicate a commercial message. To that end, we apply a content analysis in the 50 most viewed music videos in YouTube in January 2013. We apply both quantitative and qualitative methodologies according to Méndiz that enumerate and evaluate the presence of brands on the screen. After the analysis, we conclude that this commercial strategy is extraordinarily usual, although not all music videos are suitable to include this kind of commercial messages. In the same way, some products and brands have found in this audio-visual format a right way to introduce their novelties in the market. Otherwise, the proximity to the television ads grammar is detrimental to the credibility of the discourse.

Keywords:

Product placement; music video; YouTube; advertising; cultural industries. 


\section{Introducción}

Entre los diferentes métodos de financiación de una producción audiovisual se incluye el product placement, que podríamos entender -aun definiéndolo de una forma provisional- como una táctica integrada dentro de la comunicación comercial de una empresa, un producto o un servicio, caracterizada por la integración que hace de una marca o del producto dentro de un discurso audiovisual de ficción, como resultado de una negociación comercial con la empresa o institución anunciante. De este modo, resulta una forma de comunicación híbrida que mezcla mensajes de muy diverso género y con distintos objetivos en un mismo formato y a través de un mismo canal, desde la unidad que origina el motivo creativo que da pie a cada estrategia de comunicación: el producto audiovisual.

Dentro de la amplia variedad de formatos de ficción audiovisuales, hemos centrado nuestra atención en el videoclip, como producto creado por las industrias discográficas con un objetivo comercial, la promoción de un single o la creación de una identidad de marca en torno a un intérprete. El vídeo musical se ha convertido también en la última década en un formato receptor de otros mensajes comerciales asociados a la presencia de productos o marcas dentro del propio discurso. Hemos tomado para su análisis un conjunto de vídeos musicales producidos en 2012 que hacen uso del emplazamiento de marcas.

El product placement se erige como una alternativa frecuente de las empresas en la transmisión de un mensaje comercial a través de la relación de simbiosis con la productora, al contribuir a financiar la producción. Con tanta tradición -según diversas fuentes- como el propio cine (o la producción de contenidos audiovisuales, podríamos generalizar) y estudiado desde distintas perspectivas, especialmente desde la cuestión de su eficacia, el emplazamiento de productos se mantiene, con todo, como un motivo de investigación capaz aún de procurar nuevas conclusiones.

Nuestro objetivo principal es conocer a través del análisis de qué forma se utiliza esta técnica de comunicación comercial en el formato del vídeo musical. Prestamos especial atención a las categorías de productos presentes en los títulos analizados, con objeto de reconocer las diferentes aplicaciones de la acción comunicativa que nos atañe en el vídeo musical. Somos plenamente conscientes de las limitaciones que este estudio encontraría en la posible evaluación de la eficacia comunicativa de cada una de las acciones referidas, por lo que no podemos confirmar con certeza la efectividad del recurso publicitario, si bien hemos intentado determinar la idoneidad del formato musical para la comunicación de un mensaje comercial a partir del análisis e interpretación de las producciones seleccionadas.

Tampoco debemos olvidar que el discurso audiovisual aparece en un contexto permanentemente en cambio donde las reglas del juego comercial y de la industria están en continua transformación. Las propuestas de acciones eficaces en un formato audiovisual no tienen por qué serlo para otro, de la misma forma que las opciones para la producción en un enclave geográfico, histórico, social o cultural no tienen tampoco por qué ser exportables para otro. 
Sostenemos la siguiente hipótesis: el emplazamiento de productos y marcas en el videoclip encuentra las importantes limitaciones a su aplicación procedentes de la propia naturaleza industrial y cultural del formato que le sirve de soporte. La razón de la incorrecta integración del product placement en el discurso procedería de un relieve excesivo del mismo, al punto de sacrificar la credibilidad del videoclip como producto cultural.

Tomamos como punto de partida las investigaciones previas con respecto a nuestro objeto de estudio para así establecer un marco teórico creado desde la crítica. A través de este hemos delimitado, en primer lugar, el concepto de product placement, al tiempo que hemos atendido a las cuestiones que más han preocupado en relación a esta estrategia de comunicación, para continuar con el intento de formulación de una definición de videoclip y la descripción del contexto condicionante en que se formula. En una segunda fase, establecemos la metodología de análisis de contenido que aplicaremos al campo de estudio y determinamos un criterio de selección de una muestra de videoclips. Hemos de considerar que se trata de un análisis de contenido a partir de una muestra seleccionada desde criterios cuantitativos. Hemos expuesto los resultados de la aplicación de la metodología de análisis a la muestra de estudio a través de una tabla y los hemos contrastados para responder a las cuestiones que nuestra hipótesis y objetivos formulan, al tiempo que llegamos a conclusiones acerca de la validez de la metodología.

La bibliografía acerca del product placement es muy abundante, si bien tomamos como referentes un número muy preciso de aportaciones, dada la reiteración con la que muchos estudios realizan las mismas afirmaciones y llegan a idénticas conclusiones. Entre los manuales básicos en español, destacaremos el estudio de Méndiz (2000) acerca de nuevas formas de patrocinio y el de Victoria Mas (1999), específico sobre el emplazamiento de productos en la cinematografía de Hollywood. Entre los artículos científicos más útiles a los propósitos de esta investigación se encuentran los firmados por Kootz (2001), Williams et al. (2011), Walton (2010), Antonopoulou (2010) o Del Pino y Olivares (2007); la cercanía en el tiempo de publicación de este material intenta de este modo garantizar la actualidad del estado de la cuestión.

En cuanto a las referencias bibliográficas acerca del videoclip, señala Jones (2005: 84) refiriéndose tanto al formato como a la MTV, que fue abundante durante los años ochenta, en los que el vídeo musical era novedoso y captó la atención de numerosas revistas de comunicación, si bien el interés pasó en los noventa, momento a partir del cual decae el número de libros sobre esta temática. Jones cita los trabajos de Auferheide en 1986 o Sherman y Domink, también en 1986, como muestra de esos trabajos de referencia.

En el caso español, podríamos añadir el de Durá en 1988, pionero en el acercamiento analítico y crítico del fenómeno es nuestro país. Añadamos también en la actualidad los trabajos de Sedeño (2007) y Selva (2012), imprescindibles en cualquier estudio sobre el tema que quiera considerar los condicionantes presentes del género, junto a trabajos concretos de Vernallis (2010), así como Middleton y Beebe o Austerlitz (a los que no citamos en este trabajo). En estos trabajos se han analizado numerosas cuestiones, apunta Viñuela (2008: 237), "paralelas a los debates acerca de su definición y su origen, 
tales como su estructura narrativa, su naturaleza comercial o su inmediatez y futilidad en relación a otros géneros audiovisuales como el cine o el videoarte".

Aunque el formato no despierta las pasiones de antaño entre los investigadores, interesados por cuestiones más recientes relativas a la cultura juvenil, consideramos que no debe ser ignorado a la vista del estimulante panorama que tiene ante sí y del renacimiento que el audiovisual en Internet ha provocado en él.

El estudio específico de la actualización de la táctica comercial en el discurso del vídeo musical apenas ha sido investigada desde un ámbito científico, aunque ha sido motivo de diferentes artículos periodísticos. Destacamos, con todo, el trabajo de Roozen y Claeys (2009), a partir del estudio de las reacciones de dos grupos experimentales expuestos a diversos vídeos musicales.

\section{1. product placement}

Son muchos los investigadores que han enunciado diversas definiciones de emplazamiento de producto y todas ellas vienen coincidir en muchos aspectos como descripción eficaz de una práctica publicitaria iniciada antes de que hubiera conciencia de la misma o una definición precisa. Es así como Méndiz lo entiende como "la inclusión de productos o servicios comerciales en obras cinematográficas o televisivas a cambio de un cierto pago o de una colaboración en la promoción de esas obras" (Méndiz, 2000: 44). Victoria amplía el concepto entendiéndolo como una comunicación comercial en virtud de la cual las marcas, a través de su integración con un evento por lo general de ficción audiovisual, son beneficiadas en su comunicación estratégica, a cambio de una colaboración diversa, de financiación o de promoción del evento (Victoria, 1999: 142-143). Williams, Petrosky, Hernández y Page (2011: 2) lo describieron como la práctica de marketing en publicidad y promoción basada en la incorporación intencionada marcas, productos o mercancía comercial en una película, programa de televisión o cualquier otro medio con objetivos comerciales. Gómez y Pérez (2004: 186) subrayan el hecho de que la marca se introduce en un contexto de comunicación en principio no publicitaria, con independencia del formato o género audiovisual en que se incorpora. Antonopoulou (2010:4) pondría el acento en el objetivo último de dicha táctica promocional: incrementar el interés del consumidor en el producto.

Frente a estas líneas de concepción del emplazamiento de productos, no excluyentes entre sí aunque centradas en diferentes particularidades, Del Pino y Olivares (2007: 343) preferirán hablar de brand placement como concepto más amplio y complejo que abarca el product placement y que definen como toda presencia intencional de una marca identificada con claridad "lograda mediante una gestión y negociación con la productora, integrada en el contexto especial y/o narrativo del género en la ficción cinematográfica y televisiva”. A diferencia del anterior concepto de product placement, el brand placement no se concebiría como mero elemento de atrezzo, sino como una estrategia (no una táctica), componente de una mezcla de fórmulas comunicativas y comerciales, un ejercicio de integración que amplía "los horizontes con una gestión 
estratégica de esos vínculos entre las marcas y corporaciones y los productos cinematográficos y televisivos" (Del Pino y Olivares, 2007: 348).

El emplazamiento de productos nace como una alternativa a la publicidad tradicional que pretende no parecerla: la nueva publicidad, apuntan Del Pino y Olivares (2007: 364), tiende a enmascarar su propia naturaleza y disfrazar su apariencia mutando a otros formatos menos convencionales. El crecimiento en conocimiento (o experiencia) del receptor del mensaje publicitario y la saturación informativa comercial a la que está siendo expuesto de forma permanente le hizo llegar a rechazar una información altamente persuasiva e insistente que no tenía por qué conciliarse con los intereses del ciudadano. Entre las reacciones de las empresas y sus estrategias de comunicación se halló la forma de introducir dicho contenido comercial en productos ante los cuales el consumidor podía "bajar la guardia", como hacía al disfrutar del visionado de una película o de un programa de televisión. La sola presencia del producto en el contexto ficcional audiovisual no implicaría una influencia directa en la acción de adquisición del espectador, ni demostraría ser más eficaz que la publicidad convencional, pero sí contribuiría a crearle una imagen en torno a un producto o una marca, al ubicarla en un entorno que caracterizaría escenarios, personajes o estilos de vida. El espectador comprendería así, mediante una puesta en escena práctica y funcional, el estilo de vida del que formaría parte al tomar un café en Starbucks o hacer uso de un iPhone. El receptor del mensaje sería cómplice del emplazamiento al aceptar que el uso que haría del producto no tendría por qué equipararlo a los personajes de la ficción.

La evaluación de la efectividad es precisamente el objetivo más habitual en las investigaciones científicas acerca del emplazamiento de productos, según apunta Walton (2010: 71). Sin embargo, esta eficacia no puede ser comprobada con facilidad: Méndiz (2000: 89) afirma que su valor no puede medirse de igual manera a como se mide el valor o la eficacia de un spot. La clave del emplazamiento, añade, se encuentra en la credibilidad que se aporta a las marcas y en la ausencia de control del anunciante con respecto al propio emplazamiento o la vida productiva del mismo.

El spot de televisión puede ser integrado como parte de una programación acerca de la cual se obtienen datos de alcance en audiencia que precisan el nivel de llegada al espectador, al tiempo que se pueden medir los cambios en ventas del producto anunciado de una forma inmediata. Sin embargo, con el product placement el anunciante nunca tendrá la seguridad de que la presencia de su marca o el modo en que es usado su producto llegue a la audiencia, ni que lo haga en el modo en que le interesa. Incluso aunque tengamos datos muy precisos de la audiencia que pudiera tener un film, no implicaría la atención apropiada ni la aceptación por parte del público de la integración de la marca en el discurso; al fin y al cabo, el pago de la entrada legitima al espectador como receptor exigente que no tiene por qué tolerar la inclusión de un mensaje comercial no deseado; el espectador también financia con el pago de su entrada el producto audiovisual que va a consumir. Antonopoulou (2010: 14) apunta entre los inconvenientes de la estrategia tanto la posible falta de percepción de la marca por el receptor como el peligro de comprometer la integridad de la historia, al poder parecer una inclusión en 
el discurso o en el relato forzada, agresiva o ridícula. El propio protagonismo de la marca, sostiene Morgado (2010: 4), podría ser tan marcado que restase atención a los personajes y el público pudiera reaccionar de una forma negativa ante la marca.

Para que el uso de esta herramienta comunicativa fuera eficaz a los objetivos del anunciante habría de integrar de forma correcta el emplazamiento en el contexto en el que aparece (Méndiz, 2000: 51), al tiempo que potenciara la marca en la mente del consumidor antes que incrementar las ventas inmediata y mostrara la cotidianeidad del producto, como elemento doméstico de la vida cotidiana. Es en estos casos cuando se produciría el esperado resultado de transferencia de la imagen de la producción de ficción al anunciante. Las marcas son entonces reconocidas con mayor frecuencia, llevando a un cambio de actitud positiva hacia las marcas, lo cual, en todo caso, no implicaría unas mejores reacciones en lo relativo al consumo del producto.

\subsection{El videoclip, formato en evolución permanente}

Podríamos definir a priori el videoclip como una producción audiovisual condicionada por sus objetivos, generalmente comerciales y común en muchos aspectos a la publicidad televisiva, colindante formalmente con elecciones estéticas cercanas a la vanguardia y la experimentación, pero sometida a criterios de mercado muy estrictos que delimitan el acabado formal del producto. Como producto audiovisual promocional tiene por objetivos la difusión de unos contenidos culturales o ideológicos y el logro una rentabilidad que compense la inversión realizada. El videoclip nace destinado principalmente a fomentar el consumo musical de una producción discográfica, con frecuencia entre sectores juveniles, cuando no se trata de una producción espontánea creada con un objetivo altruista o artístico.

La definición del clip musical en cuanto a sus objetivos en el contexto de las industrias culturales debe replantearse a partir del amplio desarrollo de lo que se ha dado en llamar Web 2.0 y, con ello, la aparición del usuario productor. Las nuevas formas de comunicación online han procurado una suerte de nuevos agentes de una comunicación potencialmente masiva y universal para los que ha dejado de ser precisa la profesionalidad que permitía el acceso a los (exclusivos) medios convencionales y la proyección comercial o propagandística de sus contenidos.

El intento de definición del formato no está exento de dificultades. Vernallis (2010: 236) llega a preguntarse por la naturaleza del vídeo musical actual desde el momento en que considera que las viejas definiciones parecen no funcionar:YouTube o el nuevo cine digital musical rompen las ataduras del formato con sus características definitorias, afirma. El videoclip ha mezclado e incorporado siempre técnicas de otros medios, pero ahora los indicadores de producción, recepción u objetivos se han perdido y no han sido reemplazados, dificultando la identificación de los rasgos del vídeo musical de hoy. Vernallis argumenta que los vídeos musicales de YouTube reflejan ahora una estética diferente a los primeros emitidos en televisión y que solo pueden ser comprendidos si se comprende la plataforma YouTube. 
Viñuela (2008: 236) va más allá de Vernallis y llega a negar la posibilidad de una definición válida para el formato, ni siquiera en un contexto previo: su versatilidad, sostiene, "es sin duda una de las razones que ha imposibilitado hasta la fecha tanto la elaboración de una definición válida de este producto, como el consenso a la hora de establecer su origen”.

Desde el momento en que varían los condicionantes que definen el clip dentro de una estructura industrial, cambia su definición desde la producción. Proponemos volver a una definición formal del videoclip, a fin de ampliar su concepto, como formato audiovisual de breve duración en el que el componente visual se subordina al sonoro. Tarín Cañadas (2012: 154) apunta, en este sentido, una definición del videoclip que creemos apropiada: "aunque la finalidad del videoclip sea la promoción (...) es una creación audiovisual que construye un relato, en la interrelación de música e imagen, que se confiere como una obra única".

Como producto perteneciente a las industrias culturales, el vídeo musical depende de las condiciones extradiscursivas en la que se produce y se difunde. Si hasta hace poco más de una década la vía principal de distribución era la televisión -lo que imponía una selección entre aquellos intérpretes que podían tener acceso a la misma y los que no-, actualmente el medio de difusión de los clips musicales son las páginas web de música y discográficas y, muy especialmente, portales de vídeo online como YouTube o Vimeo. La televisión generalista dio la espalda a este tipo de contenidos hace años, dejando de ser programados, y quedó como reducto de canales especializados de cable y satélite. Las franquicias internacionales de MTV en abierto se ocuparon con una programación no musical y YouTube se consolidó como plataforma de acceso al videoclip.

La industria discográfica atravesaba una de sus peores crisis con la expansión de los programas P2P como Napster que, desde 1999, permitía a los usuarios compartir archivos de música sin necesidad de intermediarios. Los derivados de Napster y las descargas directas terminaron por minar el comercio del formato físico y la industria reaccionó, aunque tarde, atendiendo a las ventajas del nuevo modelo de negocio digital, en el que se legalizaba la descarga a través de distribuidores virtuales oficiales. De igual modo, tras unos primeros años de disputas legales con portales como YouTube, se alcanzaron acuerdos en los que las discográficas dotaban de contenidos al portal, al tiempo que se servían de las ventajas de la promoción del portal y de un porcentaje de ingresos por publicidad. YouTube se convertía así en un poderoso aliado para la promoción de contenidos de la industria discográfica a través de un formato óptimo para su distribución en la plataforma, el videoclip.

En la distribución de contenidos a través de Internet las discográficas encuentran una indudable ventaja con respecto a medios como la radio o la televisión: la independencia en la promoción a través de estos le permite ofrecer su producto de forma directa. De igual forma, puede comercializar su producto a través de intermediarios como iTunes. Por el contrario, no tienen el alcance inmediato y simultáneo de la televisión o la radio, aunque puede llegar a superar el número de receptores de los medios convencionales en cierto margen de tiempo. 
Desde el momento en que la emisora de televisión no media en la difusión del vídeo musical, el formato ha ganado en libertad tanto en cuestiones formales (por ejemplo, en la duración de los mismos o la articulación de estrategias narrativas crossmedia) como en aspectos extradiscursivos relativos a la propia producción. La situación de crisis de la industria discográfica ha procurado diferentes tendencias vinculadas con la financiación del videoclip, entre ellas la reducción al máximo de la inversión necesaria para la producción (dado el éxito de vídeos en YouTube low-budget, por su bajo presupuesto), o la potenciación de fórmulas alternativas de financiación, caso del product placement. Si la MTV imponía un control sobre la presencia de mensajes comerciales en los vídeos programados, la distribución prioritaria a través de portales de vídeo online como YouTube elimina las restricciones previas en sus contenidos. Ello posibilita, de esta forma, el crecimiento en las estrategias que ligan la imagen de un intérprete a un producto o marca.

\section{Metodología}

El análisis de contenido puede entenderse como un conjunto de operaciones aplicadas sobre un objeto determinado, señalan Casetti y Di Chio (1991: 17), consiste en su descomposición y sucesiva recomposición con el fin de identificar mejor los principios de su construcción y funcionamiento. En nuestro caso nos permitirá descubrir de qué forma se aplica el emplazamiento de marcas en el formato objeto de nuestro estudio. A la hora de abordar el análisis del product placement en los videoclips seleccionados aplicaremos la metodología de análisis de contenido propuesta por el profesor Méndiz (2000: 91 y ss.), quien establece seis variables, cuatro de análisis estrictamente cuantitativo y dos de análisis parcialmente cuantitativo/cualitativo. Este esquema metodológico resulta útil y eficaz en la extracción de conclusiones, razón por la cual abogamos por su aplicación. Otras propuestas analíticas más recientes no varían en lo sustancial la atención a las distintas variables. Las categorías del análisis serían las siguientes:

1) Producto, referido a la descripción del artículo presente en el discurso.

2) Marca, nombre concreto de la compañía comercial a la que pertenece el producto presentado, o la mera presencia de la marca sin su producto.

3) Tipo de product placement, que dividiremos en tres grupos: emplazamiento verbal (en el que la marca se menciona de forma explícita), emplazamiento activo (en el cual el producto cobra cierto protagonismo en la acción) y emplazamiento pasivo (que permite la visualización de la marca).

4) Tipo de presencia, según la focalización que la marca tendrá en pantalla, y que podrá ser como plano protagonista (por delante del personaje), plano neutro (en el mismo eje o campo de acción que el personaje) o como plano fondo (por lo general en el decorado). 
5) Relación con el contexto, donde valoraremos el grado de adecuación del emplazamiento en cinco categorías: Definidor, si el producto o marca define a los personajes; Natural, en el caso de que no defina al personaje pero se integre en la acción; Indiferente, cuando la aparición de una marca no aporta connotaciones con la trama o los personajes; Artificial, en el caso de que el emplazamiento sea forzado o rompa la armonía de un escenario; y Contradictorio, cuando además de haber conflicto con su entorno se niegan elementos de coherencia de la historia o los personajes.

6) Duración, medición del tiempo de exposición del producto. Ante las dificultades que el cálculo de la duración suponía, hemos optado por indicar el minutaje del emplazamiento.

A partir de estas herramientas hemos analizado el uso que se ha dado del emplazamiento de productos en los videoclips de producción reciente, datos que puestos en relación nos permiten conocer las diferentes aplicaciones que sigue la estrategia y el punto actual en el que queda, apuntando así a posibles desarrollos en el futuro.

La muestra de vídeos musicales que hagamos es determinante a la hora de obtener unos resultados objetivos, por lo que se trata de un aspecto que hemos cuidado. Dado que pretendemos atender a la presencia de product placement en un discurso condicionado por su nuevo medio de distribución masivo, las plataformas de vídeo online, tomaremos la muestra a partir de los contenidos dispuestos por YouTube, portal, como ya apuntamos, paradigmático en el consumo del formato y nuevo referente de alcance de los productos de la industria discográfica. Dentro de la amplia cantidad de clips presentes en el portal propiedad de Google, que no solo cuenta con piezas nacidas tras su nacimiento, en 2005, sino muy anteriores, hemos seleccionado producciones recientes en el tiempo; dado que nuestra atención apunta a las tendencias en la actualidad de la táctica comercial, hemos atendido a la lista ofrecida por YouTube de los vídeos musicales más reproducidos a lo largo de un mes, enero de 2013. Creemos que restringir la muestra al consumo durante un mes nos permite acceder a las piezas con mayor reconocimiento en el momento contemporáneo al análisis. En esta selección, la mayor parte de las producciones analizadas pertenece a 2012 y sólo dos casos son de 2010 y 2011.

Por otra parte, las listas de consumo masivo recogerán las principales demandas del usuario de YouTube, condicionado por poderosas campañas mediáticas o por fenómenos virales más o menos espontáneos. La selección de una muestra a partir del reconocimiento social y de la industria de una pieza audiovisual limita los condicionantes y las posibilidades de las que parte el análisis, ofreciendo posiblemente conclusiones tendentes en algún aspecto determinado. Sin embargo, consideramos que supone un criterio válido dado lo representativo de la misma: mostraría la apuesta de la industria (en la promoción de sus productos a través de YouTube), así como la aceptación por parte del público objetivo, por lo general el usuario joven.

Desde el momento en que recurrimos a los listados de mayor consumo eliminamos también criterios más subjetivos en la selección de piezas. Queremos evitar también el azar a la hora de elegir la muestra porque implicaría la elección de un 
método aleatorio para su selección que terminaría por encontrar los propios límites que el portal ofrece en el acceso a sus contenidos. El azar en la selección de la muestra que analizaremos no implicaría, de igual forma, una mayor representatividad en los resultados.

YouTube permite conocer los contenidos más reproducidos de forma general o por categorías según la categorización de la pieza hecha por el usuario o canal que lo distribuye, por países o de forma global, así como atendiendo a diferentes márgenes temporales (históricos o desde los orígenes de su puesta en marcha, durante los últimos 30 días, durante los últimos siete días o durante las últimas 24 horas). Hemos seleccionado los 50 vídeos más reproducidos dentro de la categoría Música durante un mes a nivel global: buscamos una muestra abierta al desarrollo general de la pieza y no particular de una demanda nacional concreta.

En cuanto a la categoría Música, hemos de apuntar que no es exclusiva de los videoclips y que incluye otros formatos, como actuaciones para televisión o promociones, que quedarán fuera de esta muestra. Es así como hemos descartado los siguientes contenidos para ser analizados: Girls' Generation I Got A Boy_Dance Teaser (promoción de 30 segundos adelanto de un vídeo musical pendiente de edición), All I Want For Christmas Is You - Mariah Carey (imagen fija con un fondo musical de una canción editada en 1994 que volvió a los hits de singles más vendidos en las navidades de 2012, sin contar un videoclip promocional reciente), Minecraft Style - A Parody of PSY's Gangnam Style (animación que parodia el clip del mismo título de PSY), PSY - Gangnam Style @ Summer Stand Live Concert (actuación musical en directo para televisión), Wham! - Last Christmas (videoclip producido en el año 1984 difundido ampliamente durante las navidades del año 2012 desde las redes sociales, que no representa el videoclip actual) y PSY - Gangnam Style M/V Making Film (reportaje a modo de making off de un videoclip).

El número de clips analizados es de 50. Aunque un trabajo que pretende determinar la relevancia del product placement como estrategia comercial aplicada al videoclip podría tener un número posiblemente superior, creemos que el incremento de la muestra no aportaría conclusiones significativas, además de sobrepasar los objetivos y extensión de este estudio. Debemos además mencionar que el listado ofrecido por YouTube es de las 96 piezas más reproducidas dentro de la categoría Música, lo que limita también la proporción de la muestra.

Los videoclips analizados son los siguientes: PSY - Gangnam Style M/V, Rihanna - Diamonds, PSY (ft. Hyuna) 오빤 딱 내 스 타일, Taylor Swift - I Knew You Were Trouble, Will.i.am - Scream \& Shoutft. Britney Spears, Justin Bieber - Beauty And A Beat ft. Nicki Minaj, Bruno Mars - Locked Out Of Heaven [Official Video], Carly Rae Jepsen - Call Me Maybe, Maroon 5 - One More Night, One Direction - Little Things, David Guetta - She Wolf (Falling To Pieces) ft. Sia, Taylor Swift - We Are Never Ever Getting Back Together, One Direction - Live While We're Young, One Direction - What Makes You Beautiful, Macklemore \& Ryan Lewis - Thrift Shop Feat. Wanz (Official Video), Alicia Keys - Girl On Fire, Katy Perry - Wide Awake, One Pound Fish $£ 1$ Fish Man - O-Fish-AlVideo, Justin Bieber - Boyfriend, Justin Bieber - As Long As You Love Me ft. Big Sean, Don't You Worry Child (Live), One Direction - One Thing, Maroon 5 - Payphone (Explicit) ft. Wiz Khalifa, Adele - Rolling In The Deep, P!nk - 
Try, Weekend - Ona Tańczy Dla Mnie - Official Video Clip, Adele - Someone Like You, Nicki Minaj - Va Va Voom (Explicit), Ke\$ha - Die Young (Official), Daddy Yankee - Limbo, David Guetta - Titanium ft. Sia, Flo Rida - I Cry [Official Video], Cher Lloyd - Want U Back (US Version), Justin Bieber - Baby ft. Ludacris, Twinkle Twinkle Little Star, Gotye - Somebody That I Used To Know (feat. Kimbra), Jennifer Lopez - On The Floor ft. Pitbull, LMFAO - Party Rock Anthem ft. Lauren Bennett, GoonRock, Te Pintaron Pajaritos [Video Oficial] - Yandar \& Yostin Feat. Andy Rivera ${ }^{\circledR}$ HD, Calvin Harris - Sweet Nothing ft. Florence Welch, Pitbull - Don't Stop The Partyft. TJR, Coldplay - Paradise, The Script - Hall of Fameft. will.i.am, Chris Brown - Don't Wake Me Up, Wisin \& Yandel - Algo Me Gusta De Tift. Chris Brown, T-Pain, Skrillex - Bangarang feat. Sirah [Official Music Video], Adele - Skyfall (Lyric Video), Michel Teló - Ai Se Eu Te Pego - Oficial (Assim você me mata), David Guetta - Turn Me Onft. Nicki Minaj, Will.i.am - This Is Love ft. Eva Simons.

Esta muestra, con todo, no representa el groso de la producción del vídeo musical, sino, como hemos apuntado, aquellas piezas con una mayor demanda y consumo por parte de los usuarios de YouTube que copan las listas con mayor número de reproducciones.

\section{Resultados y discusión}

Hemos representado en primer lugar una tabla en la que recogemos los resultados de la aplicación de la metodología elegida en la muestra seleccionada para su análisis. Hemos descartado en esta tabla aquellas piezas que no activaban la estrategia comercial de nuestro interés, por lo que recogeremos los resultados ofrecidos por los 19 vídeos musicales con presencia de productos o marcas identificables.

Cuadro 1. Presencia de productos o marcas en videoclips de YouTube (semana 1/1/2013).

\begin{tabular}{|c|l|l|l|l|l|l|l|}
\hline $\begin{array}{c}\text { Título del } \\
\text { videoclip }\end{array}$ & \multicolumn{1}{|c|}{ Producto } & \multicolumn{1}{|c|}{ Marca } & No & \multicolumn{1}{c|}{ Tipo } & \multicolumn{1}{c|}{ Plano } & Contexto & Min. \\
\hline & $\begin{array}{l}\text { Funda para móvil } \\
\text { con objetivo }\end{array}$ & Iam+ para iPhone & 2 & Activo & Protagonista & Artificial & $\begin{array}{l}00: 52 \\
03: 37\end{array}$ \\
\cline { 2 - 8 } & Tableta & iPad & 2 & Activo & Protagonista & Artificial & $\begin{array}{l}01: 07 \\
02: 46\end{array}$ \\
\cline { 2 - 8 } $\begin{array}{l}\text { Will.i.am - } \\
\text { Scream \& } \\
\text { Shout ft. Brit- } \\
\text { ney Spears }\end{array}$ & $\begin{array}{l}\text { Funda para móvil } \\
\text { sumergible }\end{array}$ & Otterbox para iPhone & 1 & Activo & Protagonista & Artificial & $01: 16$ \\
\cline { 2 - 8 } & Prótesis de mano & i-limb Ultra (Touch Bionics) & 1 & Activo & Protagonista & Artificial & $01: 26$ \\
\hline
\end{tabular}




\begin{tabular}{|c|c|c|c|c|c|c|c|}
\hline $\begin{array}{l}\text { Título del } \\
\text { videoclip }\end{array}$ & Producto & Marca & No & Tipo & Plano & Contexto & Min. \\
\hline \multirow{4}{*}{$\begin{array}{l}\text { Will.i.am - } \\
\text { Scream \& } \\
\text { Shout ft. Brit- } \\
\text { ney Spears }\end{array}$} & Impresora 3D & Makerbot & 4 & Activo & Protagonista & Artificial & $\begin{array}{l}01: 38 \\
03: 30 \\
04: 31 \\
04: 38\end{array}$ \\
\hline & Mezcladora & Native Instruments & 2 & Activo & Protagonista & Artificial & \begin{tabular}{|l|}
$01: 48$ \\
$03: 31$ \\
\end{tabular} \\
\hline & Altavoces & Beats by Dre & 2 & Activo & Protagonista & Artificial & \begin{tabular}{|l|}
$03: 01$ \\
$03: 10$ \\
\end{tabular} \\
\hline & $\begin{array}{l}\text { Funda para móvil } \\
\text { con objetivo }\end{array}$ & Iam+ para iPhone & 5 & Pasivo & Neutro & Natural & $\begin{array}{l}03: 12 \\
03: 24 \\
03: 42 \\
04: 08 \\
04: 32\end{array}$ \\
\hline $\begin{array}{l}\text { Justin Bieber } \\
\text { - Beauty And } \\
\text { A Beat ft. } \\
\text { Nicki Minaj } \\
\end{array}$ & Videojuego & Just Dance 4 & 5 & Activo & Neutro & Natural & $\begin{array}{l}00: 18 \\
04: 05 \\
04: 22 \\
04: 25 \\
\end{array}$ \\
\hline $\begin{array}{l}\text { Bruno Mars - } \\
\text { Locked Out Of } \\
\text { Heaven [Offi- } \\
\text { cial Video] }\end{array}$ & $\begin{array}{l}\text { Caja de ritmos elec- } \\
\text { trónica }\end{array}$ & Akai & 2 & Activo & Protagonista & Natural & $\begin{array}{l}00: 17 \\
01: 29\end{array}$ \\
\hline \multirow{3}{*}{$\begin{array}{l}\text { Macklemore } \\
\text { \& Ryan Lewis } \\
\text { - Thrift Shop } \\
\text { Feat. Wanz } \\
\text { (Official } \\
\text { Video) }\end{array}$} & Bebida no alcohólica & Slurp & 3 & Activo & Neutro & Natural & $\begin{array}{l}00: 18 \\
00: 21 \\
00: 30 \\
\end{array}$ \\
\hline & Automóvil & Delorean & 1 & Activo & Protagonista & Natural & $00: 25$ \\
\hline & Bolsa de viaje & British Airways & 3 & Pasivo & Fondo & Indiferente & $\begin{array}{l}02: 24 \\
02: 51\end{array}$ \\
\hline $\begin{array}{l}\text { Alicia Keys - } \\
\text { Girl On Fire }\end{array}$ & Auriculares & Sony & 1 & Pasivo & Neutro & Natural & 03:07 \\
\hline
\end{tabular}




\begin{tabular}{|c|c|c|c|c|c|c|c|}
\hline $\begin{array}{l}\text { Título del } \\
\text { videoclip }\end{array}$ & Producto & Marca & No & Tipo & Plano & Contexto & Min. \\
\hline \multirow{2}{*}{$\begin{array}{l}\text { Alicia Keys - } \\
\text { Girl On Fire }\end{array}$} & Auriculares & Sony & 1 & Activo & Neutro & Natural & 03:11 \\
\hline & Gafas de sol & Bulgari & 1 & Activo & Protagonista & Definidor & 03:30 \\
\hline $\begin{array}{l}\text { Justin Bieber } \\
\text { - Boyfriend }\end{array}$ & $\begin{array}{l}\text { Teléfono móvil } \\
\text { (prototipo) }\end{array}$ & iPhone & 1 & Activo & Protagonista & Natural & 00:20 \\
\hline $\begin{array}{l}\text { Justin Bieber } \\
\text { - As Long As } \\
\text { You Love Me } \\
\text { ft. Big Sean }\end{array}$ & Automóvil & Rolls Royce & 2 & Pasivo & Fondo & Definidor & $\begin{array}{l}04: 0604 \\
: 28\end{array}$ \\
\hline $\begin{array}{l}\text { One Direc- } \\
\text { tion - One } \\
\text { Thing }\end{array}$ & Autobús & Signbus & 7 & Pasivo & Fondo & Indiferente & 00:00 \\
\hline $\begin{array}{l}\text { Maroon } 5 \text { - } \\
\text { Payphone } \\
\text { (Explicit) ft. } \\
\text { Wiz Khalifa }\end{array}$ & Automóvil & GTB & 1 & Pasivo & Fondo & Indiferente & 02:18 \\
\hline $\begin{array}{l}\text { Cher Lloyd - } \\
\text { Want U Back } \\
\text { (US Version) }\end{array}$ & Pizarra & Coca Cola & 1 & Pasivo & Fondo & Indiferente & 02:31 \\
\hline \multirow{3}{*}{$\begin{array}{l}\text { Justin Bieber } \\
\text { - Baby ft. } \\
\text { Ludacris }\end{array}$} & Hostelería & City Food & 3 & Pasivo & Fondo & Indiferente & $\begin{array}{l}00: 15 \\
00: 27 \\
03: 23\end{array}$ \\
\hline & Hostelería & Hard Rock Café & 2 & Pasivo & Fondo & Indiferente & $\begin{array}{l}00: 06 \\
00: 43\end{array}$ \\
\hline & Centro comercial & Citywalk Hollywood & 3 & Pasivo & Fondo & Indiferente & $\begin{array}{l}\text { 00:02 } \\
\text { 00:08 } \\
\text { 02:09 }\end{array}$ \\
\hline
\end{tabular}




\begin{tabular}{|c|c|c|c|c|c|c|c|}
\hline $\begin{array}{l}\text { Título del } \\
\text { videoclip }\end{array}$ & Producto & Marca & No & Tipo & Plano & Contexto & Min \\
\hline $\begin{array}{l}\text { Justin Bieber } \\
\text { - Baby ft. } \\
\text { Ludacris }\end{array}$ & Salas de cine & Cinemas & 10 & Pasivo & Fondo & Indiferente & $\begin{array}{l}00: 05 \\
00: 26 \\
00: 41 \\
00: 46 \\
00: 51 \\
01: 04 \\
01: 41 \\
02: 10 \\
02: 41 \\
03: 22\end{array}$ \\
\hline \multirow{3}{*}{$\begin{array}{l}\text { Jennifer } \\
\text { Lopez - On } \\
\text { The Floor ft. } \\
\text { Pitbull }\end{array}$} & Automóvil & BMW & 2 & Activo & Protagonista & Natural & $\begin{array}{l}\text { 00:07 } \\
\text { 00:09 }\end{array}$ \\
\hline & Pendientes & Swaroski & 1 & Activo & Protagonista & Definidor & $00: 19$ \\
\hline & Bebida alcohólica & Royal Crown & 3 & Activo & Protagonista & Natural & $\begin{array}{l}02: 26 \\
02: 34 \\
02: 43 \\
\end{array}$ \\
\hline \multirow{6}{*}{$\begin{array}{l}\text { LMFAO - } \\
\text { Party Rock } \\
\text { Anthem ft. } \\
\text { Lauren Ben- } \\
\text { nett, } \\
\text { GoonRock }\end{array}$} & Automóvil & Hyundai & 1 & Pasivo & Fondo & Indiferente & $00: 47$ \\
\hline & Automóvil & Mini & 1 & Pasivo & Fondo & Indiferente & 01:02 \\
\hline & Teléfono móvil & iPhone & 1 & Activo & Protagonista & Natural & 01:36 \\
\hline & Auriculares & Beats by Dre & 1 & Activo & Protagonista & Natural & 01:58 \\
\hline & Automóvil & Audi & 1 & Pasivo & Fondo & Indiferente & 01:58 \\
\hline & Bebida no alcohólica & Cherrytree Cola & 1 & Activo & Protagonista & Artificial & 04:21 \\
\hline $\begin{array}{l}\text { Calvin Harris } \\
\text { - Sweet No- } \\
\text { thing ft. } \\
\text { Florence } \\
\text { Welch }\end{array}$ & $\begin{array}{l}\text { Máquina de recreati- } \\
\text { vos }\end{array}$ & Sega Rally & 1 & Pasivo & Fondo & Indiferente & 03:31 \\
\hline
\end{tabular}




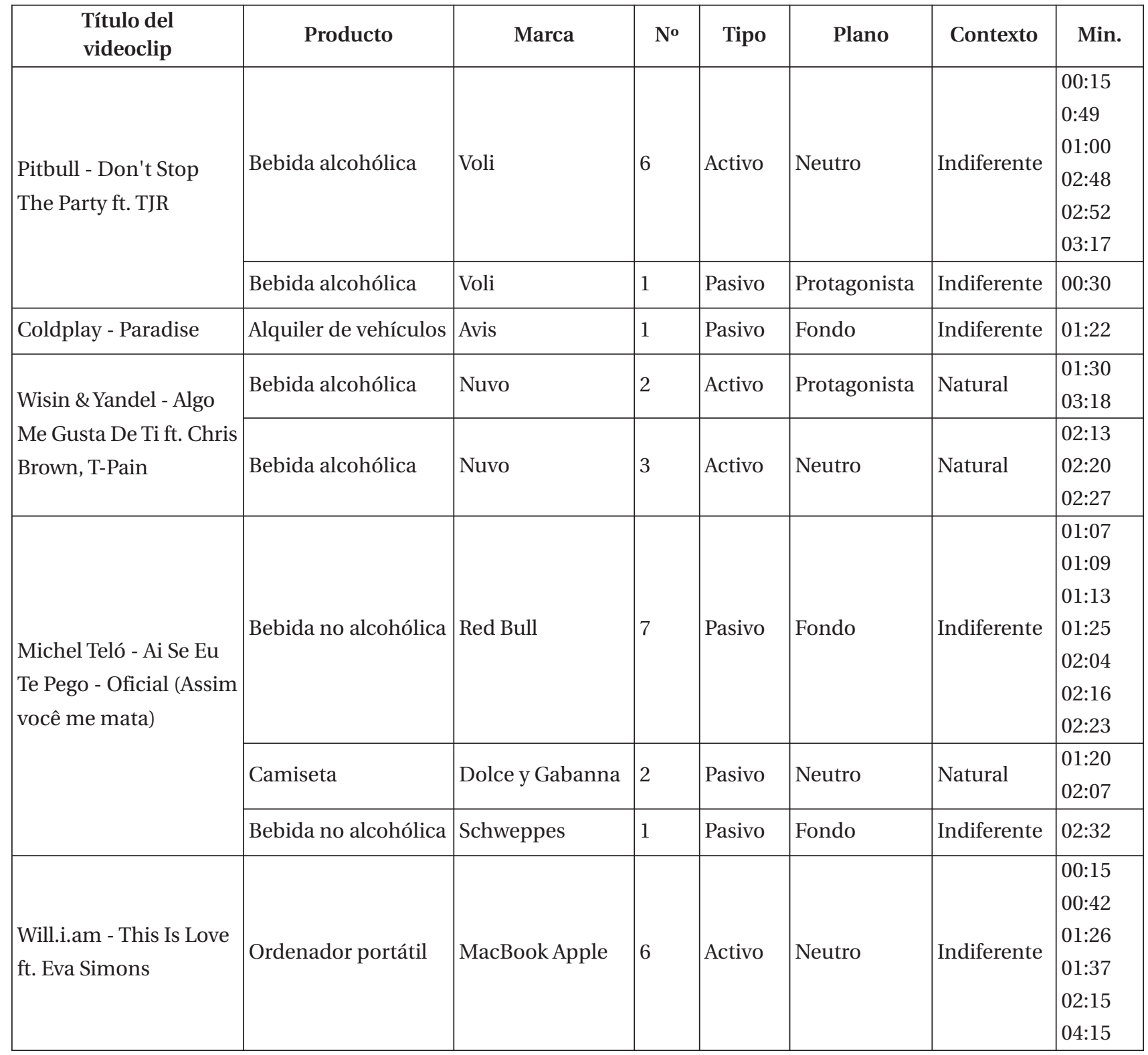

Fuente: Elaboración propia 
Con respecto a los resultados que ofrece nuestro análisis, destacamos el hecho de que 19 de los 50 vídeos analizados contaba con emplazamiento de productos, es decir, un $38 \%$ de la muestra. Aunque nuestra intención no era determinar el porcentaje de producciones que activan esta estrategia, hecho que requeriría de una muestra más amplia y unos objetivos más ambiciosos, este ratio viene a confirmarnos la frecuencia de su recurso como método de financiación. Precisamos que, desde el momento en que analizamos los vídeos con mayor número de reproducciones, este porcentaje representaría la presencia de product placement en los clips con mayor aceptación por parte del usuario y con mayores expectativas comerciales, no del total de la producción de videoclips. Con todo, este porcentaje resulta representativo de la asiduidad con que se recurre a la activación del emplazamiento publicitario en el clip musical.

No disponemos de datos relativos a la producción de años precedentes, pero nuestra experiencia como seguidores del formato, más intuitiva que científica, nos hace ver que en la actualidad el recurso es mucho más habitual que en décadas previas y no supone la excepción sino una estrategia de financiación cotidiana, a la vista de la importante presencia dentro de la muestra analizada. Este hecho se explicaría, como ya apuntamos, desde la inestabilidad de la industria discográfica, la necesidad de rentabilizar al máximo sus inversiones y de diversificación de su negocio (aun siendo el producto musical su eje) y desde la libertad en cuanto a contenidos que la independencia de los canales televisivos permite la distribución a través de Internet.

Una de las conclusiones a las que llega nuestro análisis es que no todos los videoclips son apropiados para el emplazamiento de productos. Aquellos con una abierta intención artística, cercanos al vídeo-arte, verían sacrificada su credibilidad si subordinaran el discurso a la función comercial que exigiría la presencia de la marca. Vídeos con un fuerte contenido melodramático como Somebody That I Used To Know de Gotye o Someone Like You de Adele romperían la intensidad de su discurso o distraerían la atención del espectador con la integración de marcas comerciales.

Esta valoración es consecuencia de la interpretación del carácter de las piezas que no hacen uso de la estrategia comercial. El clip musical mantiene un vínculo muy próximo con la producción de vídeo-arte y subordinar las ambiciones artísticas de aquel a la presencia de marcas evidenciaría la función comercial y promocional del vídeo, provocando posiblemente la decepción del espectador.

Tampoco serían adecuados aquellos vídeos musicales en los que la introducción de un producto podría perjudicar su imagen de la marca. En el clip de Rihanna Diamonds se representa un accidente de tráfico: no querríamos conducir ese automóvil, razón por la que no identificamos su procedencia. Como caso real podemos citar el del videoclip de Ke\$ha Die Young, en una primera edición la intérprete aparecía utilizando un móvil Nokia de la gama Lumia con el sistema operativo Windows Phone 8. Pocos días después la presencia del dispositivo desaparecía del clip, sin que Nokia o Microsoft explicaran la razón de su decisión. Aunque algunos blogs apuntan a las malas críticas recogidas en YouTube por la presencia de la marca y su mensaje comercial, hemos de apuntar también que el propio desarrollo argumental de la pieza tampoco 
beneficiaba a las compañías anunciantes: en el clip, la intérprete representa ser una adoradora del diablo que irrumpe bruscamente en una iglesia, mostrando multitud de símbolos de la secta de los illuminati.

Por el contrario, dada la frecuencia con que aparecen en nuestro listado, determinados productos han encontrado en el vídeo musical una vía óptima para su presencia en un modo natural y sin discordancias. Serían productos cotidianos y próximos a los espectadores del videoclip pero también a los personajes del discurso desarrollado en la pieza, como pueden ser vehículos, vestuario y accesorios y, muy especialmente, dispositivos tecnológicos. Las comunicaciones entre personajes a través de teléfonos móviles, ordenadores o tabletas hacen el discurso apropiado para la aparición de marcas, sin que sea una presencia que sacrifique la credibilidad de la narración.

La idoneidad del emplazamiento de este tipo de productos procedería, en todo caso, de la coherencia con el contexto en que aparece. En aquellos casos en los que fuera artificial o contradictorio, la presencia de la marca evidenciaría el objetivo comercial del discurso, arriesgando con ello la eficacia del emplazamiento. Podría ser el caso del vídeo de Will.I.am y Britney Spears Scream and shout, con frecuentes insertos de la línea de productos diseñados por el intérprete para el iPhone de Apple; el vídeo se convierte prácticamente en un spot comercial con abundantes planos detalles (protagonistas, pues) de los productos, insertos en el contexto de un modo artificial. Aunque el clip es descriptivo (es decir, no narrativo) y recoge únicamente imágenes de personajes en entornos neutros realizando coreografías, los insertos en plano corto de los dispositivos resultan gratuitos. Contribuyen a dar al discurso un tono de sofisticación y glamour procedente también de la exclusiva tecnología recogida en sus planos, pero no aportan información que contribuya a construir un discurso narrativo o visual coherente en sí mismo.

Si atendemos a la distribución en diferentes categorías de los aspectos analizados, de los 45 emplazamientos de productos contabilizados un $55,5 \%$ sería de tipo activo y un $44,4 \%$ pasivo, no localizando ninguno verbal. Este hecho pondría de relieve la funcionalidad de la integración del producto y, con ello, la voluntad de que el que el mensaje comercial no pase por alto para el espectador. El riesgo del product placement pasivo sería pasar desapercibido para el espectador, si bien no juega con la posible ruptura de la integridad del discurso, como puede ocurrir con el activo.

La razón, por otra, de la ausencia de product placement verbal se encuentra en el propio carácter del videoclip, en el que el protagonismo de la banda musical está por encima, en el plano sonoro, de cualquier otro tipo de elemento. Aunque cada vez son más frecuentes los vídeos con escenas o diálogos al margen de la canción o paralelos a la misma, no son aprovechados para que los personajes citen marcas. Existiría otra posibilidad de emplazamiento de productos, a través de la mención de la marca en el texto de la canción. En la muestra analizada no hemos localizado ningún caso, pese a tratarse de una práctica de interrelación entre publicidad y creación artística cada vez más habitual.

Con respecto al tipo de presencia, es decir, la focalización de la marca en pantalla, hemos localizado un $44 \%$ de casos en los que el plano es protagonista, como tendencia mayoritaria, seguido de un $20 \%$ en que el plano es neutro y un $35,5 \%$ de 
fondo. Por lo general, el plano será protagonista en aquellos casos en los que se hace un uso activo del producto y será fondo en los casos de presencia pasiva. Los planos neutros (en el mismo eje de acción que el personaje) son pasivos o activos, sin que en este caso el eje en que aparece el producto venga condicionado por su funcionalidad.

Esta focalización prioritaria del producto o marca aproxima el lenguaje del videoclip al del spot audiovisual, en el que son frecuentes los planos cortos de productos y marcas para identificarlos ante la audiencia. En estos casos la función comercial de la pieza audiovisual queda en evidencia.

Los porcentajes de distribución en los tipos de relación con el contexto mostrarían los siguientes resultados: solo un 6,6\% sería definidor, lo que implicaría una escasa implicación de los personajes o los intérpretes presentes en el vídeo musical; un 33,3\% es natural, con marcas presentes en entornos en los que no son coherentes, como ocurre con las bebidas en las escenas de fiestas o de locales de ocio nocturno; en un $40 \%$ la relación con el contexto es indiferente, lo que puede llevar a un emplazamiento más forzado; y un $20 \%$ sería artificial, como el caso mencionado de los productos diseñados por Will.I.am en Scream and Shout. Aunque no encontramos ningún ejemplo de contextos contradictorios, la suma de los casos indiferentes y artificiales llega al $60 \%$, hecho que podría explicar un emplazamiento poco verosímil del producto o la marca, comprometiendo con ello la credibilidad del discurso artístico y evidenciando su objetivo comercial.

Como en el resto de formatos en que se aplica la presencia de marcas, el principal problema procede de la artificialidad de introducción de las mismas. En el videoclip la narratividad no entra tanto en peligro desde el momento en que los clips descriptivos (no narrativos) son muy frecuentes, pero a pesar de ello la marca debería integrarse con naturalidad en el discurso, y hacerlo de una forma convincente y realista con el contexto en que aparece.

Hemos tomado nota también el minutaje del emplazamiento de productos, aunque no la duración. Podemos, no obstante, comentar que el ritmo de edición del vídeo musical obliga al uso de planos de duración muy breve que puede no beneficiar la correcta exploración del mismo y, en particular, de la marca, razón por la cual la escasa duración del plano debe compensarse con el tamaño del plano, más cercano y llenando el encuadre. Este tipo de insertos compromete, de nuevo, la credibilidad de la pieza. De igual forma, la ruptura del ritmo acelerado del montaje en el videoclip para insertar planos con un mensaje comercial contribuye de nuevo a la ruptura de la coherencia del discurso.

Una introducción más natural de la marca en la que fuera perceptible implicaría un ritmo de montaje adecuado. Los clips basados en la sucesión de planos a muy alta velocidad encuentran así una dificultad añadida a la inserción de la marca de forma natural pero también eficaz, de cara a su percepción.

La aplicación del esquema analítico sobre la muestra seleccionada ha permitido llegar a algunas conclusiones de tipo metodológico. En primer lugar, debemos mencionar la dificultad que algunos casos ofrecieron en el reconocimiento de la presencia de un producto como product placement: podemos intuir, por ejemplo, que las gafas de sol que lleva el intérprete 
de hip hop Flo Rida ( $\mathrm{Cry}$ ) procedan de alguna casa notoria en la producción de este tipo de lentes, pero la ausencia de una marca que nos permite identificarlas evita su categorización como product placement. Otro tanto de lo mismo ocurre en la pieza de Justin Bieber Boyfriend, donde el cantante conduce o aparece entre vehículos de alta gama que un especialista en el sector reconocerá, pero que el profano en la materia desconocerá, al no aparecer ningún elemento gráfico que lo identifique.

¿Hasta qué punto podríamos determinar si esta presencia de productos actúa como product placement o no? A partir del visionado y análisis del vídeo tampoco podemos conocer si ha habido algún acuerdo contractual entre empresas y discográficas para activar una estrategia comercial que financie la producción del clip.

Hemos identificado como product placement aquellos casos en los que hemos reconocido una presencia reconocible de la marca de una compañía o de un producto cuyas particularidades físicas lo hacen inmediatamente identificable. Es el caso, por ejemplo, del teléfono iPhone, presente en varios de los vídeos analizados: el frontal del dispositivo no cuenta con ningún elemento gráfico o logotipo de la compañía Apple, pero la cotidianeidad del producto y su sobreexposición mediática hacen la presencia del producto reconocida.

De igual forma, hemos descartado del análisis de estas actuaciones aquellos casos en los que se ha ocultado intencionadamente la marca del producto, aunque hayamos sido capaces de identificarla. Uno de los componentes de la banda de Carly Rae Jepse (Call Me Maybe) toca un instrumento de la casa Roland, si bien la letra ele del logotipo aparece oculta, con lo que podemos leer en el lateral del mismo Ro and, lo que dificulta su identificación. Otro tanto de lo mismo ocurre en el clip de The Script Hall of Fame, en el que el casco protector de un boxeador oculta una de las letras de la marca Reyes, empresa consolidada en este tipo de productos, con lo cual entendemos que no hay una intención de uso comercial en su presencia.

Contar el número de apariciones de un producto también ha procurado cierta complejidad, desde el momento en que el montaje acelerado de algunos vídeos ha fragmentado un plano con emplazamiento de productos en varios planos de pocos frames con otros planos intercalados con otros. Sería el caso, por ejemplo, del vídeo Algo me gusta de ti de Wisin \& Yandel, en el que un plano corto del giro de una botella de vodka Nuvo es interrumpido con planos muy breves intercalados. Hemos contabilizado este emplazamiento como uno solo, al tratarse de un mismo plano, aun fragmentado. Hicimos de igual forma en el clip On the Floor de Jennifer López en el que la acción de llenar un vaso de ron Royal Crown es recogido en tres planos editados en continuidad.

\section{Conclusiones}

Una vez aplicado el análisis de contenido a los vídeos musicales preferidos por los usuarios de YouTube en el mes de enero de 2013, llegamos a las siguientes conclusiones: 
- Confirmamos la hipótesis de partida, según la cual el videoclip encuentra importantes limitaciones en el modo de hacer un uso coherente del emplazamiento de productos en el formato, de donde resultan piezas en las que el mensaje comercial es demasiado obvio. Lo hacemos desde la frecuencia con que los casos analizados de product placement son de tipo activo, en un plano protagonista y frecuentemente con una relación con el contexto indiferente, cuando no artificial.

La evidencia del objetivo comercial procede no ya solo de la presencia del mensaje publicitario paralelo al musical sino de la coincidencia en recursos y lenguaje con los anuncios de televisión; la similitud con el spot desde la actualización de los mismos recursos (por ejemplo, a través de planos en los que la marca o el producto es focalizado en primer plano con una duración que rompe el ritmo en la edición de los planos previos) hace consciente al espectador de este vídeo musical del discurso publicitario, pudiendo influir en su relación (de aceptación o rechazo) ante el visionado de aquel. No olvidemos que el videoclip no deja de ser un producto con un objetivo comercial, si bien se reviste de un lenguaje que le otorgue un valor independiente como producto desde sus valores artísticos. La integración del product placement convierte así al vídeo musical en un meta-discurso publicitario, como formato promocional con un segundo objetivo comercial.

-La evidencia de la función comercial sacrificaría la intención artística que se le ha supuesto al vídeo musical hasta ahora, virando su concepto hacia una funcionalidad comercial aún más evidente. La subordinación del producto creado por las industrias discográficas hacia objetivos promocionales o de creación de imagen de marca podría perjudica igualmente la credibilidad del intérprete como artista. El artista se aleja así de la imagen de "creador" de un producto cultural para integrarse dentro del mercado de una forma aún más abierta para el receptor del mensaje. Aunque todo intérprete que trabaja para las industrias culturales lo hace integrado en un sistema comercial, en este caso como elemento productor, este hecho quedaba en segundo plano para el ciudadano, quien se siente atraído por las bondades de su producción musical antes que por su poder de creación de demanda de consumo. El product placement evidencia el carácter comercial de la producción cultural y liga la imagen del intérprete con la de elemento de reclamo publicitario.

- Podríamos argumentar, por otra parte, que el videoclip ha perdido su carácter de discurso audiovisual ligado a la vanguardia e incluso a la industria del entretenimiento para convertirse en producciones más comerciales, cuando no abiertamente en spots televisivos de mayor duración. La pérdida de la vinculación con intenciones más artísticas dejaría a un lado el debate acerca de la credibilidad del creador al subordinar su producción a la transmisión de un mensaje comercial.

- Podríamos igualmente apuntar la idea de que en la relación entre la imagen del músico (que podríamos considerar una marca en sí) y la del producto o marca se produce una transferencia de valores que puede beneficiar al intérprete y a la compañía publicitada, en especial cuando entre ambos hay un trasvase de valores positivos que potencien el poder de atracción de ambos elementos. Como señala Isidro Moreno (2003: 17), el product placement busca un impacto mayor que el que obtendría mediante los anuncios convencionales "gracias al mimetismo por simpatía que tratan de producir". Es desde aquí que el fan puede sentirse más cercano a su ídolo musical, consumiendo los productos a los que asocia su imagen. 
- La promoción de un vídeo musical se realiza en periodos de tiempo muy precisos y tiene una escasa vigencia pasada la vida comercial de la producción discográfica. Este hecho puede perjudicar la confianza en la eficacia del product placement en un periodo superior de tiempo, pero resulta efectivo en el caso de las estrategias publicitarias que introducen nuevos productos que serán comercializados de forma simultánea a la promoción del producto musical ligado al videoclip. Por ello que vídeos musicales se han utilizado para la presentación de nuevos productos, cuando no directamente prototipos, que se adelantan incluso a la misma comercialización del producto. La demanda del nuevo producto (habitualmente dispositivos tecnológicos) vendrá de la mano pues de la difusión del vídeo musical.

\section{Referencias bibliográficas}

Antonopoulou, V. (2010): "Product Placement in Film". Georgian National Film Center. Disponible en Internet: http://gnfc.ge/uploads/Researches\%20-\%20kvlevebi\%20/Product\%20Placement_International.pdf [Consultado el $14 / 02 / 2013]$

Casetti, F. y Di Chio, F. (1991): Cómo analizar un film. Barcelona: Paidós.

Del Pino, C. y Olivares, F. (2007): "Brand placement y advertainment: integración y fusión entre la ficción audiovisual y las marcas”, Zer, n. 22, pp. 341-367. Disponible en Internet: http://orff.uc3m.es/bitstream/10016/9626/1/ZER\%2022_pino.pdf [Consultado el 14/02/2013]

Gómez Pérez, F. J. y Pérez Rufí, J. P. (2004): “Implicaciones del product placement en el discurso cinematográfico”, en Mínguez Arranz, N. y Villagra García, N. (eds.): La comunicación: nuevos discursos y perspectivas. Madrid: Edipo, pp. 185-190.

Jones, S. (2005): “MTV: The Medium as the Message”, Critical Studies in Media Communication, n 22, pp. 83-88. Disponible en Internet: http://stevejones.me/pubs/2005/CSMC-MTV.pdf [Consultado el 14/02/2013]

Kootz, A. (2001): "Selling the Bond Image. Merchandizing and Product Placement in the James Bond Movies. Licence to Thrill. Reading James Bond as a Cultural Phenomenon”, 1sr Annual Students Conference. Berlín: Humboltd-Universität zu Berlin. Disponible en Internet: http://www2.hu-berlin.de/amerika/asc/bond/007_kootz.pdf [Consultado el 14/02/2013]

Méndiz, A. (2000): Nuevas formas publicitarias. Patrocinio, Product Placement, Publicidad en Internet. Málaga: Universidad de Málaga.

Moreno, I. (2003): Narrativa audiovisual publicitaria. Barcelona: Paidós.

Morgado, M. M. (2010). “Del product placement no se escapa nadie”, en AA.VV.: Jornades de Foment de la Investigaciò. Castellón de la Plana: Universitat Jaume I. Disponible en Internet: http://www.uji.es/bin/publ/edicions/jfil3/36.pdf [Consultado el 14/02/2013]

Roozen, I. y Caléis, C. (2009): “Are We Aware of Product Placements in Music Videos?”, Hub Research Paper Economics and Management. Disponible en Internet: https:/ /irias.hubrussel.be/bitstream/123456789/2869/1/09HRP38.pdf [Consultado el 14/02/2013] 
Sedeño, A. M. (2007): “El videoclip como mercanarrativa”, Signa: Revista de la Asociación Española de Semiótica, nº 16, pp. 493-504. Disponible en Internet: http://descargas.cervantesvirtual.com/servlet/SirveObras/67922841091203897443679/ 026026.pdf?incr=1 [Consultado el 14/02/2013]

Selva, D. (2012): “Nuevos fenómenos en el entorno on line. La difusión del videoclip a través de Internet”, Telos, no 93. Disponible en Internet: http://sociedadinformacion.fundacion.telefonica.com/DYC/TELOS/REVISTA/Perspectivas 90TELOS_PERSPECT3/seccion=1236\&idioma=es_ES\&id=2012020211040001\&activo=7.do [Consultado el 14/02/2013]

Tarín Cañadas, M. (2012): “La narrativa en el videoclip Knives Out, de Michel Gondry”, Icono 14, Vol. X, no 2, pp. 148-167. Disponible en Internet: http://www.icono14.net/ojs/index.php/icono14/article/view/482/365 [Consultado el 14/02/2013]

Vernallis, C. (2010): "Music Video and YouTube: New Aesthetics and Generic Transformations”, en Keazor, H. y Wübbena, T. (eds.): Rewind, Play, Flashforward: The Past, Present and Future of the Music Video (Cultural and Media Studies), Bielefed: Transcript Verlag, pp. 235-261. Disponible en Internet el 7/2/2013 en: https://ccrma.stanford.edu/courses/ 32n/15_Vernallis_videophone.pdf [Consultado el 14/02/2013]

Victoria Mas, J. S. (1999): Hollywood y las marcas (Product Placement). Navarra: Newbook Ediciones.

Viñuela Suárez, E. (2008): “La autoría en el vídeo musical: signo de identidad y estrategia comercial”, Revista Garoza, n 8, pp. 235-247. Disponible en Internet: http://webs.ono.com/garoza/G8-Vinuela.pdf [Consultado el 14/02/2013]

Walton, A, (2010): “The Evolution of Product Placement in Film”, The Elon Journal of Undergraduate Research in Communications, n. 1, pp. 70-85. Disponible en Internet: http://www.elon.edu/docs/e-web/academics/communications/ research/07WaltonEJSpring10.pdf [Consultado el 14/02/2013]

Williams, K., Petrosky, A., Hernández, E. y Page, R. (2011): “Product placement effectiveness: revisited and renewed”, Journal of Management and Marketing research, n. 7, Disponible en Internet: http://www.aabri.com/manuscripts/10712.pdf [Consultado el 14/02/2013] 